\title{
Spontaneous Preterm Birth
}

National Cancer Institute

\section{Source}

National Cancer Institute. Spontaneous Preterm Birth. NCI Thesaurus. Code C112864.

Preterm birth from 20 weeks to 36 weeks, 6 days of gestation associated with one of the following: classic preterm labor or preterm premature rupture of membranes. 